•保护论坛・

\title{
以国家公园为主体的自然保护地体系立法思考
}

\author{
吕忠梅* \\ (清华大学法学院, 北京 100811)
}

\begin{abstract}
摘要: 实现十九大报告提出的建立以国家公园为主体的自然保护地体系的改革目标需要法治保障。建设自然保护 地体系涉及的不同生态系统和多个管理部门、多方利益主体, 是一个巨大的复杂系统, 需要进行整体性、系统性 的立法研究。目前, 国家正在推进国家公园体制改革并已将《国家公园法》列入十三届全国人大常委会立法计划。 更需要我们从自然保护地立法体系建设的高度, 正确处理《国家公园法》与未来可能制定的《自然保护地法》的 关系, 在《国家公园法》制定过程中为今后出台《自然保护地法》预留空间, 并建立相应的衔接机制, 统筹谋划并 协同推进国家公园法与自然保护地立法。
\end{abstract}

关键词: 自然保护地; 国家公园; 自然保护地法; 国家公园法

\section{Systematic legislation for nature conservation with national parks as the main body}

\author{
Zhongmei Lü* \\ School of Law, Tshinghua University, Beijing 100811
}

\begin{abstract}
The rule-of-law is necessary to achieve reform goals of establishing a protected area system with national parks as the main body, which was proposed in the Report of the Nineteenth CPC National Congress. The establishment of the protected area system involves various ecosystems, administrative agencies, and stakeholders. It is a very complicated process requiring holistic and systematic legislative research. Currently in China, the State is promoting a reform of the national park system and has listed the National Park Law in the legislative plan of the thirteenth National People's Congress. It is necessary to correctly manage the relationship between the National Park Law and a possible future law of protected areas. Systematic legislation and legislative space for the Law of Protected Areas within the National Park Law are required to establish a connecting mechanism and to coordinate and promote in a concerted manner the National Park Law and the Law of Protected Areas.
\end{abstract}

Key words: nature conservation land; national parks; Law of Protected Areas; National Park Law

十九大以来, 自然保护地体系建设作为生态文 明体制改革的重要内容, 受到党和国家的高度重视, 2019年1月23日, 习近平总书记主持召开中央全面 深化改革委员会第六次会议, 审议通过《关于建立 以国家公园为主体的自然保护地体系指导意见》(以 下简称《意见》), 表明自然保护地建设将以整体性、 协调性方式推进。自2004年全国人大常委会首次将 《自然保护区法》列入立法计划以来, 到2018年十 三届全国人大常委会将《国家公园法》列入立法计
划, 相关法律的制定经历了曲折反复。梳理各种观 点发现, 虽然各方面都在呼吁进行“顶层设计”并鼎 力推动, 但《国家公园法》或《自然保护地法》始 终面目模糊, 共识并未达成。如何站在新时代的新 起点上, 以习近平生态文明思想为指引, 全面认识 自然保护地体系建设过程中的生态保护与经济、社 会发展的关系, 深入研究与自然保护地建设有关的 各种利益诉求与保障条件、现行法律冲突与空白, 建立有说服力的《自然保护地法》基础理论与技术 
方案，是必须回答的现实课题。

\section{1 国家自然保护地体系改革方案提出了基 法需求}

建立自然保护地是迄今为止最有效的保护自 然生态系统、维护生物多样性的理想模式(Lausche, 2016; 唐芳林，2018)。但建设自然保护地体系涉及 森林、湿地、荒漠、海洋等不同生态系统和多个管 理部门、多方利益主体, 是一个复杂的系统工程。 国家公园与自然保护地立法, 核心是要将这个复杂 的系统工程所涉及的各种利益关系予以妥善调整, 建立人与自然、人与人之间的双重和谐秩序 (Lausche, 2016)。只有正确认识自然保护地体系的 方位与使命, 才可能解决立法的基本需求。

\section{1 国家公园改革试点是自然保护地体系建设的 重要组成部分}

回顾自十八大以来的国家公园体制改革进程, 从提出国家公园体制改革的任务, 到明确提出建立 国家公园为主体的自然保护地体系建设目标, 将国 家公园改革作为自然保护地体系重要组成部分的 思路日益清晰。

十八届三中全会《中共中央关于全面深化改革 若干重大问题的决定》明确提出要推进国家公园改 革, 强调“实行最严格的源头保护制度、损害赔偿制 度、责任追究制度, 完善环境治理和生态修复制度, 用制度保护生态环境”。“十三五”规划纲要对国家公 园体制改革做了进一步细化, 明确以风景名胜区、

森林公园、湿地公园、沙漠公园等为国家公园的保 护范围; 以典型生态系统、物种、基因和景观多样 性为保护重点; 以构建自然资源资产产权制度、确 定产权主体、创新产权实现形式, 适度开发公众休 闲、旅游观光、生态康养服务和产品, 实施生态移 民等为保护路径; 以保护优先、自然恢复为主, 构 建生态廊道和生物多样性保护网络为保护原则; 以 全面提升各类自然生态系统稳定性和生态服务功 能, 筑牢生态安全屏障为保护目标 (http://www.xinhuanet.com//politics/2016lh/2016-03/1 7/c_1118366322.htm)。《国家公园体制改革总体方 案》做出了具体安排, 明确了国家公园改革任务是 “加强自然生态系统原真性、完整性保护为基础, 以 实现国家所有、全民共享、世代传承为目标, 理顺 管理体制, 创新运营机制, 健全法治保障, 强化监
督管理，构建统一规范高效的中国特色国家公园体 制，建立分类科学、保护有力的自然保护地体系” (http://politics.people.com.cn/n1/2017/0927/c1001-29 561108.html)。改革主要路径是：将创新体制和完善 机制放在优先位置，进行相关部门职能整合; 既进 行总体布局又分布推进, 在提出空间布局、明确数 量规模的基础上，成熟一个设立一个。确立了生态 保护第一、国家代表性、全民公益性的基本原则。 并特别强调, 进行国家公园体制改革目标是构建以 国家公园为代表的自然保护地体系。

十九大报告明确提出要建立“以国家公园为主 体的自然保护地体系”, 澄清了国家公园与自然保 护地不是“替代”关系, 进一步强调国家公园改革的 “先行先试” 性质, 改革的最终目标是要建立完整的 自然保护地体系。2019年1月，《关于建立以国家公 园为主体的自然保护地体系指导意见》进一步强调: 要按照山水林田湖草是一个生命共同体的理念, 创 新自然保护地管理体制机制, 实施自然保护地统一 设置、分级管理、分区管控, 把具有国家代表性的 重要自然生态系统纳入国家公园体系, 实行严格保 护, 形成以国家公园为主体、自然保护区为基础、 各类自然公园为补充的自然保护地管理体系。这表 明, 国家公园是中国自然保护地最重要的类型, 承 担着国家国土生态安全屏障的重任, 是社会公共利 益的组成部分。通过建立国家公园体制, 改革自然 保护领域存在的问题, 是建立中国自然保护地体系 的“先手棋”。

\section{2 自然保护地管理体系建设是生态文明制度建 设的重要组成部分}

从十八大提出国家公园体制改革任务, 到十九 大报告提出建立以国家公园为主体的自然保护地 体系, 始终是将国家公园和自然保护地体系建设作 为生态文明制度建设的一项内容, 并与相关制度平 行提出。我们必须从生态文明制度建设的整体性角 度来认识国家公园和自然保护地体系建设的方位 与使命。

十八届三中全会《决定》将“加快生态文明制 度建设”作为一个专题, 进行国家公园体制改革是 生态文明建设的四项重要改革任务之一。四项改革 任务分别是: (1)建立自然资源资产产权制度和用途 管制制度(国家自然资源资产管理体制和监管体制); (2)建立生态保护红线制度(主体功能区、国土空间 
开发保护、国家公园体制); (3)建立资源有偿使用制 度和生态补偿制度 (资源税、重点生态功能区生态补 偿、地区间生态补偿); (4)建立生态环境保护管理体 制(陆海统筹的生态系统保护修复和污染防治区域 联动、国有林区经营管理体制、集体林权制度改革)。 由此可见, 国家公园体制改革从开始就不是一项单 独的任务, 而是作为生态保护红线制度的重要组成 部分, 需要与主体功能区制度、国土空间开发保护 共同推进。

十九大报告更加突出了改革的系统性、协调 性。在“加快生态文明制度改革，建设美丽中国”部 分, 提出“改革生态环境监管体制。加强对生态文明 建设的总体设计和组织领导，设立国有自然资源资 产管理和自然生态监管机构, 完善生态环境管理制 度，统一行使全民所有自然资源资产所有者职责， 统一行使所有国土空间用途管制和生态保护修复 职责，统一行使监管城乡各类污染排放和行政执法 职责。构建国土空间开发保护制度, 完善主体功能 区配套政策，建立以国家公园为主体的自然保护地 体系。坚决制止和惩处破坏生态环境行为”, 再次将 自然保护地体系建设与国土空间开发保护制度、主 体功能区配套政策相并列。

由此可以看出, 自然保护地体系建设从来就不 是一项孤立的改革。它需要为自然保护地体系建设 提供所有权制度安排，以明确国家所有自然资源资 产所有权人代表为目标, 推进自然资源产权制度改 革，形成国有自然资源资产所有权人和管理者相互 独立、相互配合、相互监督的新型体制; 需要为自 然保护地体系建设提供体制机制基础, 按照山水林 田湖草是一个生命共同体的理念, 由一个部门负责 对山水林田湖草进行统一保护、统一修复, 推进对 管辖范围内所有国土空间的用途管制, 实现管理体 制改革; 需要为国家公园和自然保护地立法提供实 践经验, 以国家公园体制改革为试点示范, 优化保 护地体系, 实施统一事权、分级管理实践, 探索建 立统一管理机构。只有这些改革措施系统进行、协 同发力, 才可能完成对自然生态空间和自然资源资 产的统一管理改革, 实现对生态环境的严格保护、 系统保护和整体保护。

\section{3 国家公园体制改革实践迫切需要完善自然保 护地体系建设的顶层设计}

为推进自然保护地体系建设和体制改革, 国家
出台国务院机构改革方案，组建新的自然资源部、 设立林草局并大力推进国家公园体制改革 (http://www.gov.cn/guowuyuan/2018-03/14/content_5 273856.htm), 力求以 “顶层设计+试点示范”的方式 系统推进、整体推进。

目前，改革正在迅速展开，国家公园体制改革 试点也取得了明显进展。但是, 在改革实践中也出 现了一些令人忧虑的现象(李将辉, 2019)。突出表现 为国家公园体制改革试点的推进情况不平衡，各类 国家公园与顶层设计之间的关系不清楚，各试点地 方 “各显神通”与改革目标之间的匹配度缺乏评估与 预测。有的试点实际上只是将原有不同形式的保护 地简单整合、换个牌子; 有的试点虽然探索了地方 立法方式，却由于国家公园体制改革本身不属于地 方立法权限，既不能解决根本问题，还可能有“越 权”之嫌; 有的试点由主管部门或地方政府单向推 进，未将中央与地方、中央和地方各相关部门、政 府与企业和社会等各方面的关系予以统筹考虑并 纳入改革范围。更为严重的是，国家公园体制改革 方案明确要求进行的财政投入结构性重组、多元化 投入渠道等核心改革，试点地区的改革方案基本上 没有涉及; 改革方案高度重视并置于优先地位的 “创新体制机制”要求，因缺乏基础性研究和有效设 计也难见清晰的“路线图”。虽然这些问题在改革起 步时在所难免，但必须引起高度重视。

国家公园及各种自然保护地的治理体系与治 理能力极不统一的管理现状，与国家建设“以国家 公园为主体的自然保护地管理体系”的目标和任务 还存在较大差距，成为了自然保护地体系建设面临 的最大挑战。可以预见，随着自然保护地体系建设 的迅速推进，自然保护地功能实现过程中与经济、 社会等各种功能之间的矛盾会更加尖锐，依附于不 同功能之上的多元利益也必将产生不同程度的冲 突。迫切需要有整体性系统性的制度安排, 协调自 然保护地体系建设过程中的多种功能以及依附其 上的多元利益关系，确定不同类型利益诉求的优先 位序，建立保护利益诉求的基本规则和具体制度， 协调自然保护地体系建设中可能普遍存在的功能 矛盾与多元利益冲突。法律作为国家最正式的制度 安排, 具有依靠国家机器加以实施的强制性, 是统 筹协调各种利益关系的最重要的国家治理方式。

在全面实施依法治国，推进社会主义法治国家 
建设的改革背景下, 也必须以法治思维与法治方法 协调自然保护地体系建设过程中复杂的功能矛盾 与多元利益冲突, 探索自然保护地体系建设与发展 的新途径。只有为自然保护地立法, 才能为各类保 护地的设立与保护建立硬约束, 为实现保护自然生 态系统的原真性和完整性的目标提供法治保障; 也 才能将自然保护地体系建设“保护优先、自然恢复” 为主的定位通过法律的制度化、规范化、程序化安 排落到实处。通过法律制度的合理配置行政权力、 界定市场主体的权利边界，建立不同部门之间与不 同区域之间的协调制度、监管制度、交易制度、公 众参与制度、纠纷解决制度等, 形成系统性、整体 性运行机制, 引领自然保护地体系建设与社会和谐 发展。正是在这个意义上, 自然保护地体系建设立 法先行意义重大，让各项改革都于法有据，不仅可 以节约改革成本, 更重要的是保证自然保护地体系 建设有序推进，避免出现“颠覆性错误”。

\section{2 以国家公园为主体的追然保护地体系立泣} 整体谋划

近两年来, 为国家公园和自然保护地立法的呼 声高涨。尤其是在《国家公园体制改革总体方案》 出台以后, 国家公园试点的话题升温, 各方面更加 关注国家公园立法问题。不少学者从不同角度提出 要制定《国家公园法》, 但有两个方面的争议: 一 是对《国家公园法》与《自然保护地法》的关系有 着不同解读，二是对《国家公园法》的性质定位有 不同看法(秦天宝, 2018)。在相关改革文件中, 也分 别提出了制定《国家公园法》与《自然保护地法》 的要求。目前, 《国家公园法》已被列入十三届全 国人大立法计划; 《自然保护地法》尚未明确立法 时间表。现实提出一个迫切需要解决的问题, 即必 须在把握好国家公园与自然保护地的关系的基础 上, 厘清《国家公园法》与《自然保护地法》的关 系, 确定两部法律的基本定位、立法原则、基本制 度体系, 然后再进入具体立法环节。

\section{1 自然保护地体系建设的历史使命决定了必须} 统筹考虑自然保护地立法

纵观世界各国的自然保护地立法, 由于不同政 治传统、自然保护法框架以及自然保护地定位, 形 成了不同的立法模式(Lausche, 2016)。2004年全国 人大常委会将《自然保护区法》纳入立法计划(孙佑
海和陈少云，2004)，2006年分别由不同部门草拟了 《自然保护区法(草案建议稿)》、《自然保护地法(草 案征求意见稿)》和《自然保护区域法(草案征求意 见稿)》; 2013年部分全国人大代表联名提出议案并 提出了《自然保护地法(草案建议稿)》。2018年开始, 国家林业和草原局积极推动《国家公园法》的制定 工作，也提出了草案建议稿。这些草案虽然都未真 正进入立法程序, 并且有的由立法机关推动, 有的 由部门推动, 有的由社会组织推动, 但从中可以看 出两种主要的立法模式选择: 一是系统性模式建立以自然保护地法为基础、国家公园法和其他自 然保护地法律法规为主体、相关技术标准为支撑的 自然保护地立法体系，凸显自然保护地立法的整体 性、系统性；二是主体法模式一建立以《国家公 园法》为主体，其他自然保护地类型法规为补充的 立法，突出国家公园的主体地位。笔者认为，自然 保护地法必须定位于系统性，只有统筹谋划其立法 体系的框架与内容，才能满足自然保护地建设“保 护优先，生态修复为主”的需求，符合“为子孙后代 留下更多自然遗产”的保护理念。

自然保护地体系是依托国土空间开发保护制 度和主体功能区划的自然保护措施。从生态的角度 看，自然保护地的最大特性是一定区域内的各种要 素与生物形成一个完整的系统; 从管理的角度看, 各类自然保护地涉及自然资源、生态保护、文化旅 游等多个方面, 是一个整体。在保护方面, 依托生 态红线和自然资源产权制度，对提升保护水平和能 力的期望更高; 在治理方面, 自然保护地功能直接 关系到社会经济发展和民生福祉，政府、企业、社 会都有权利也有义务，以不同方式参与自然保护地 的“改革战”; 在生态安全方面，自然保护地事关国 家兴衰和民族存亡，是国家安全的重要组成部分 (Grazia et al, 2016)。处理好自然保护地涉及的各种 法律关系，确保保护地类型完整、面积合理、功能 齐全，必须构建政府主导、企业主体、公民主动的 新的多元共治体制，探索自然保护的新途径。

自然保护地建设要实现“保护优先、自然恢复 为主”的定位，不仅要制定一部将这些因素全面考 虑、统筹谋划的综合性法律，还要根据不同自然保 护地类型特点和具体功能制定相应的基础性和支 撑性法律法规。自然保护地法体系要针对行政区划 分割自然地理空间和流域的问题，以系统性思维， 
统筹考虑自然保护地建设所涉及各地改革发展、各 项区际政策、各领域建设、各种资源要素, 建立区 域协同、合作机制，促进自然保护地实现流域协同 发展、区域互动合作, 形成生态文明建设的先行示 范区。针对一个保护区多部门分工负责的问题, 按 照生态系统规律，把自然保护地安全、生物多样性、 人居、旅游、适度利用等问题一体考虑, 建立自然 保护地统一监管制度, 切实解决自然保护地无序开 发、商业利用等问题。针对规划混乱的状况, 建立 多规合一制度, 优化自然保护地类型布局, 坚持多 种形式有机结合、多种保护方式综合运用, 不断提 升自然保护地治理水平与能力。这个意义上的自然 保护地法不是一般意义上的自然资源法，也不是自 然环境保护法, 而是自然保护地体系综合决策、保 护与利用统筹考虑、人与自然和谐发展、中央和地 方协同联动的法律制度体系，是综合行政、民事、 刑事等多种法律调整手段、实体法与程序法相互衔 接的法律系统。

\section{2 确定自然保护地体系建设的重大利益关系决} 定了必须统筹考虑自然保护地立法

自然保护地体系建设的国家战略，把保持一个 完整的、健康的自然生态系统提升到治国理政的高 度, 以改变长期存在的生态建设与经济社会发展 “不协调、不平衡”的问题。由此, 如何调整发展与 保护的关系成为了自然保护地立法需要解决的重 大利益关系。

从自然保护地体系建设的整体看, 各种类型的 自然保护地既是以生态要素为纽带和基础的自然 单元, 同时也是构成人类生产和生活的经济社会单 元, 是自然系统、管理系统、社会系统、文化系统、 法律系统等的复合体。自然保护地建设中, 生态环 境保护与经济、社会发展是一个整体, 为此必须统 筹考虑自然保护地建设与科学利用自然资源、优化 产业布局、推动地区经济社会发展的关系。这就需 要树立整体立法的理念与模式, 将一定空间范围内 各子系统之间的关系统筹考虑, 建立综合调控的法 律制度体系。

从局部发展与自然保护地体系的关系看, 自然 保护地可能涉及不同省份、区域, 不同类型自然保 护地建设诉求不一, 不同主体对自然保护地也可能 产生特定的功能诉求。随着经济社会发展, 自然资 源约束趋紧, 多元化的诉求将不可避免导致冲突与
博亦的日趋激烈; 针对自然保护地的多功能属性, 各方面的利益表达不同。比如，随着国家公园体制 改革的推进，已经批准建立的国家公园已经初步建 成并发挥作用，国家公园逐步走向保护管理的新时 期，由于国家公园改革的最终归属是由国家直接管 理，中央与地方在国家公园建设过程中的矛盾日益 显现，多主体参与治理的压力也不断加大。此外, 由于不同地方的国家公园有不同的建设基础，历史 发展所形成的产业布局、管理格局、人文传统都可 能对国家公园改革产生不同程度的影响，尤其是存 在于国家公园范围内的企业、居民的利益诉求与实 现国家公园建设目标的矛盾日益突出。如果国家公 园体制改革涉及的行政区域和不同行业、部门在思 想认识上不能形成一条心, 在实际行动中不能形成 一盘棋，把国家公园建设成为 “生态保护第一、国 家代表性、全民公益性”的目标就会变成一句空话。 这也需要统筹考虑自然保护地立法体系，建立协 同、协调的法律机制，将各类自然保护地建设所涉 及的利益关系纳入法律制度，平衡好发展与保护的 关系。

\section{3 创新自然保护地管理体制、构建多元共治体系} 决定了必须统筹考虑自然保护地立法

虽然正在推进的机构改革，尤其是自然资源部 和国家林草局的组建开启了创新自然保护地管理 体制的新窗口，但现行管理体制在很多方面不能适 应自然保护地体系建设新要求, 如何在本来就很脆 弱的生态环境条件下，依托现有资源，统筹谋划自 然保护地类型，建设合理的自然保护地体系，处理 好经济建设、社会发展、自然保护的矛盾，贯彻绿 色循环低碳发展理念，推动产业结构、增长方式、 消费模式向有利于节约能源资源和保护生态环境 的目标转型升级, 在中国前期准备不足, 实践经验 欠缺。还有一些部门和地区, 因为既得利益而对全 面推进自然保护地体制改革、创新管理体制机制认 识不到位、有抵触情绪，甚至以各种方式阻碍改革。 这更需要以突破部门利益、地方利益的藩篱的决心 和勇气强力推进体制改革，通过系统谋划自然保护 地立法体系，建立统筹协调、规划引领、市场运作 的领导体制和工作机制，促进政府主导、多元主体 积极参与、相关利益方通力协作的多元共治格局逐 步形成, 加快推进政府职能转变, 提高公共服务水 平，创造良好的自然保护地体系运行环境。 
自然保护地建设的首要任务是生态修复, 要优 先实施重大生态修复工程, 把防护林体系建设、水 土流失及岩溶地区石漠化治理、退耕还林还草、水 土保持、河湖和湿地生态保护修复等作为推动自然 保护地建设的优先选项, 增强生态系统的水源涵 养、水土保持等生态服务功能, 涉及到中央与地方 的多个管理部门、也涉及多个省(市、区); 但从目 前的法律制度看, 自然保护地建设方面的中央事权 与地方事权、地方之间的事权、中央部门事权与地 方部门事权等方面, 既缺乏划分依据, 也没有评价 标准，还欠缺健全的协调、协作机制，造成了自然 保护地治理中的不同部门公权力、公权力与私权 利、职权与职责等划分不清, 导致自然保护地各级 地方政府之间封闭、自利化管理，职能部门之间“七 虎争山”，自然保护地管理机构的事权被虚化、弱化， 政府与市场、社会、公众之间尚未形成治理合力等 问题。这些问题的解决, 从根本上有赖于统筹考虑 自然保护地立法体系, 对自然保护地事权的划分作 出系统性、科学性的制度设计和安排。

\section{4 重构法律制度、协调沟通法律部门之间的关系 决定了必须统筹考虑自然保护地立法}

随着自然保护地改革的深入推进, 自然保护 地内外经济、社会与生态环境之间, 地区间和部门 间，以及各相关产业之间的矛盾日渐突出，关系协 调和利益调整非常复杂, 权益纠纷也会越来越多。 各利益主体往往立足于自身立场, 将多元利益主张 通过 “法言法语”转化为权利的主张及冲突博弯, 力 求获取法律的支持。但是现行的立法层级较低和采 取分散立法模式，导致法制基础薄弱、法律制度相 互冲突和法律空白等问题同时存在, 不足以彻底解 决自然保护地建设过程中的严重利益冲突问题。

在立法层级方面, 自然保护地立法最为薄弱; 在生态环境保护的法律法规体系中, 与自然保护地 有关的法律法规最为薄弱, 与加强管理的客观要求 特别是自然保护地管理体制改革的现实要求极不 适应。一是国家立法滞后, 综合性的自然保护地立 法长期处于空白状态; 二是地方立法层面遭遇困境, 随着国家公园体制改革的快速推进，各种矛盾凸显， 一些地方加快了相关立法步伐, 但由于国家公园体 制改革属于中央事权, 地方立法在这方面难以真正 有所作为。目前, 我国有效的自然保护地立法仅有 《自然保护区管理条例》, 属于立法效力较低的单项
立法, 不能满足解决自然保护地问题的法律需求。

在立法模式方面，采取了资源、环境分别立法 形式(吕忠梅, 2018), 虽然在自然资源和环境保护的 相关法律中，有一些涉及自然保护地的条款，但这 些法律制度主要按照资源要素设立，缺乏对自然生 态的系统性和完整性考虑, 加之各类保护地依据各 自的法规建立、运行，缺乏国家法律统一协调，不 可避免地出现了自然保护地分类不科学、区域重 叠、保护标准不清晰、公益属性不明确、多头交叉 管理、权力与责任不明确、保护与开发矛盾难以协 调等问题。值得注意的是，由于我国实际上的行政 主导立法方式，各涉及自然保护地的管理部门容易 从各自的管理职能出发考虑自然保护问题，而导致 法律制度间的不一致、不衔接和空白。这些制度运 用到自然保护地管理中，不仅缺乏对自然保护地特 殊问题的针对性，而且可能导致法律制度实施的负 效益，出现各部门“依法打架”，因部门利益竞争而 导致自然保护地的保护目标无法实现。

因此，现行的立法体制不能适应建立自然保护 地管理体系的需要, 必须加以改革, 通过采取综合 立法方式，统筹考虑自然保护地的立法效力层次, 注重自然保护地涉及自然、行业、地区等不同要素, 具有社会、经济、文化属性复合交融的特点，系统 分析自然保护地生态系统与其他生态系统的关联 性、与经济社会发展的同构性，从制度上予以引导、 规范、预防，以满足自然保护地区位特征、自然特 性与管理特点的现实需求。

\section{3 以整体性思维处理好国家公园法与自然保} 法的关系

按照“国家公园为主体、自然保护区为基础、 各类自然公园为补充”的自然保护地格局, 我国的 自然保护地立法应该是一个综合性的立法体系，理 想模式是 “基本法 + 专类保护地法 + 技术标准”。 该立法体系理应以宪法为基础、以自然保护地基本 法为主干、以国家公园等不同类型的自然保护地法 规规章为重要组成部分、以各类标准为支撑，是一 个相互协调、相互配合的完整系统。但从现实情况 看, 十三届全国人大常委会已将《国家公园法》列 入二类立法计划, 并启动了相关立法研究工作，而

《自然保护地法》能否进入立法程序还是一个未知 数。这意味着, 《国家公园法》不仅有可能先于《自 
然保护地法》出台，而且在效力等级上还可能与《自 然保护地法》平行。这一安排客观上带来了自然保 护地立法体系建设的问题, 需要我们从自然保护地 立法体系的角度, 处理好《国家公园法》与未来可 能制定的《自然保护地法》的关系, 在《国家公园 法》中建立必要的衔接机制、预留可能的立法空间, 为形成两部法律间的制度衔接、机制协同展开深入 研究。

\section{1 积极探索《国家公园法》的法律制度创新}

国家公园体制改革承担着自然保护地体系改 革“先行先试”的重任，《国家公园法》的制定，探索 法律制度创新也是其应有之义。系统研究国家公园 法的制度创新问题, 是当前面临的紧迫任务, 也是 难点。《国家公园法》既要通过促进国家公园建设 实现自然保护地体系的制度破冰, 又要以国家公园 带动其他保护地向前发展, 解决原有㽽疾, 为中国 特色的自然保护地体系建设提供示范和成功案例。

从法律属性上看，《国家公园法》是一部“管理 法”，其主要内容是规定国家公园设立、管理、保护 和利用的基本原则、标准、职责权限、权利义务、 法律责任等等(李博炎等, 2017)。在现实情况下，国 家公园体制改革作为自然保护地建设的重要组成 部分, 自然保护地建设需要生态文明体制改革提供 支撑, 根据我国法律体系现状, 至少应从如下方面 进行《国家公园法》制度创新的探索：

一是国家公园法中的产权制度创新, 形成国家 所有自然资源所有权与使用权管理新机制。国家公 园体制改革的核心是重新划定保护区域并明确自 然资源资产的法律属性，必然涉及到自然资源所有 权及其相关法律制度。建立有效的适合国家公园体 制改革的新型产权制度, 既要以已经出台的《民法 总则》及正在编纂的《民法典物权编》建立的自然 资源权属制度为依据，也要以各自然资源法建立的 不同类型自然资源权属制度为基础, 处理好登记确 权、所有权与用益权、发展权与环境权之间的关系。

二是创新体制机制，实现从“行政管理”到“多 元共治”的转变。国家公园体制改革的重要任务是 在严格管理的同时, 在不同程度上满足人民群众旅 游休闲的需求, 这就会涉及特许经营、特许保护等 相关制度。处理好国家公园的规划权、管理权、开 发利用权、特许经营权、特别保护权等各种关系, 既 涉及不同的政府部门现有权力的调整、也涉及各利
益相关方的利益整合，需要按照“职权法定”原则重 新配置权力, 按照权利保障确认权利, 必须要解决 事权配置及权利保障的原则、标准、程序、救济等 问题，以保证《国家公园法》具有可操作性，具有 执行力。

三是创新国家公园法的利益协调机制, 形成 “共建、共享、共赢”新格局。国家公园体制改革的 主要内容是对一定的保护区域进行最严格的管理, 这意味着在国家公园法中建立一系列的限制、禁止 性制度，这是必须的。但是，国家公园立法必须解 决“既见物也见人”的问题，统筹考虑建立国家公园 可能对区域内外人民生产生活的影响，考虑限制、 禁止措施的正当性与合理性，并建立相应的利益平 衡机制，通过建立补偿、赔偿制度，保护好当地居 民的生存权、发展权以及文化多样性。

\section{2 在《国家公园法》中为自然保护地立法体系预 留制度空间}

确立《国家公园法》与《自然保护地法》有机 衔接原则，统筹考虑两部法律之间的制度关系。充 分考虑国家公园在自然保护地体系中的主体地位, 按照兼顾特殊性与一般性的思路，设计《国家公园 法》的制度体系与主要内容。

在明确了《国家公园法》是自然保护地法体系 中的骨干性法律的定位的前提下，结合《国家公园 法》先行启动的现实，对国家公园法的制度进行类 型化, 并按照与自然保护地法的关系密切程度加以 区别处理。一是对仅适用于国家公园的特殊性的制 度，不必考虑与自然保护地法的衔接问题。主要是 关于国家公园的国家属性、划定方法、国家自然资 源资产产权、中央政府保障等专门目标、原则、机 制和制度。二是可普遍适用于其他保护地类型的一 般制度，应该按照“一般与特殊”的原则，适当考虑 与自然保护地法的区别, 在《国家公园法》中更多 规定适用于国家公园的制度，如特许经营制度、地 役权制度、生态修复制度、利益相关方参与制度、 责任追究制度等。三是体现自然保护地体系基本方 向和基本原则的制度, 要考虑在《自然保护地法》 缺位的情况下，充分发挥国家公园改革先行的意义 和价值，有力规制自然保护地其他类型，防止自然 保护地改革变性变味, 在一定程度上发挥基本法的 作用，如生态系统原真性、完整性保护、全民公益 性保护的原则、目标和相关制度等(张振威和杨锐, 
2016)。

\section{3 切实推动自然保护地立法从“单项局部立法”} 到“多项综合立法”的转变

按照“建设以国家公园为主体的自然保护地体 系”的改革要求, 自然保护地建设特别需要率先在 保护目标、保护原则、类型确定、监管模式等方面 完成总体定位与顶层设计。虽然《国家公园法》的 出台, 会极大推动自然保护地的法律制度建设, 健 全相关体制机制，但自然保护地立法也有其独特内 容, 自然保护地体系的一些特殊问题也不会因《国 家公园法》的颁布而自然得到解决。我们不能忘记, 建立完善的自然保护地体系才是改革的归宿, 《国 家公园法》的制定并不代表改革任务的完成。另外, 我国现行的《自然保护区条例》是典型的“单项局 部立法”, 不能担负自然保护地立法基础的重任, 必须另起炉灶，按照“多项综合立法”的整体性思维， 重新构建《自然保护地法》的立法目标、基本原则 和制度体系。

一是确立风险预防原则。自然保护地的生态要 素与人文因素形成了不同类型自然保护地质与量 的特殊性, 客观上约束着人类生产、生活与管理活 动。鉴于自然和生物多样性保护的极端重要性, 自 然保护地建设必须坚持保护优先、自然恢复为主的 战略定位，自然保护地生态环境只能优化不能恶化， 涉及自然保护地的一切人类活动都要以不破坏生 态环境为前提。由于体制的惯性，一些地方的发展 诉求仍占据上风，违法违规行为时有发生，迫切需 要建立风险预防原则, 划定行为底线与红线, 夯实 自然保护地制度基础。因此, 根据资源环境承载能 力、现有开发状况和保护目标, 以提升、保障自然 保护地生态服务功能为诉求, 通过制定《自然保护 地法》, 对与自然保护地相关的管理行为、保护行 为与利用行为进行类型化, 建立相应的调整原则与 制度规范, 建立负面清单, 强化禁止性规定与责任 追究, 是《自然保护地法》能否取得实效的关键性 举措。

二是构建多维面向的制度体系。《自然保护地 法》作为自然保护地立法体系中的“基本法”, 具有 为各种类型自然保护地立法和制定相关技术标准 提供依据的功能，理应采取“提取公因式”方式、提 炼抽象可适用于不同类型保护地的普遍性制度。根 据制度的适用范围, 可划分为自然保护地共性制度
与自然保护地个性制度; 根据制度的空间面向，划 分为适用于自然保护地某一具体方面的“点上”制 度、涉及自然保护地某一领域的“线上”制度和广泛 运用于各类自然保护地整体的“面上”制度; 根据社 会关系规范的重要性、典型性，划分为调整重大利 益关系的核心制度和调整普通利益关系的一般制 度。《自然保护地法》主要规定共性制度、“面上制 度”和一般制度(吕忠梅, 2019)。

三是增强制度设计的针对性适用。按照生态文 明制度建设的趋势，《自然保护地法》应结合自然 保护地体系建设需求，研究创设一些新的制度，包 括拓展自然保护地空间管理的多规合一、生态红 线、生态承载能力监测评估制度，适应市场经济体 制需求的生态补偿、自然资源有偿使用制度，促进 多元共治的跨部门衔接会商、鼓励利益相关方参 与、信息公开、目标质量考核等制度。

\section{结语}

根据“建设以国家公园为主体的自然保护地”的 整体性改革目标，制定《国家公园法》时绝不能就 事论事。一方面，将要制定的《国家公园法》不应 是国家公园改革总体方案的“直译”，而是运用法律 理性、法律逻辑、法律语言的“意译”。另一方面，先 行制定的《国家公园法》既要通过促进国家公园规 范化建设实现自然保护地体系的制度破冰，又要以 国家公园治理带动其他类型保护地的发展，消除原 有㽽疾，为中国特色的自然保护地体系建设提供制 度示范和成功案例。

与此同时，应加强对自然保护地立法体系的研 究，为“形成以国家公园为主体、自然保护区为基 础、各类自然公园为补充的自然保护地管理体系” 提供法律依据。一方面，认真梳理现有的立法实践， 分析已制定的《自然保护区管理条例》、《风景名胜 区管理条例》等行政法规、规章以及地方性法规规 章的经验与教训, 厘清各种各类立法之间的关系。 另一方面，深入研究自然保护地立法的基础理论问 题，解决自然保护地立法在中国特色社会主义法律 体系中的地位、自然保护地立法的性质定位与价值 取向、自然保护地立法与环境资源立法的关系、自 然保护地立法的内在逻辑与结构、自然保护地立法 的制度体系等基础性问题，为未来制定《自然保护 地法》及相关法规、规章提供理论支撑。以充分发 
挥自然保护地的特殊功能与作用, 实现生物多样性 保护领域的“良法善治”。

\section{参考文献}

Grazia BF, Nigel D, Tilman J, Barbara L (translated by Zhu CQ, Li Y, Zhao YT) (2016) IUCN Governance of Protected Areas-From Understanding to Action. China Forestry Publishing House, Beijing. (in Chinese) [Grazia BF, Nigel D, Tilman J, Barbara L (朱春全, 李叶, 赵云涛 译) (2016) IUCN自然保护地治理一从理解到行动. 中国林业出版 社, 北京.]

Lausche B (translated by Wang X, Lu K, Tang T) (2016) Guidelines for Protected Areas Legislation. Law Press China, Beijing. (in Chinese) [Lausche B (王䂀, 卢锟, 唐瑭 译) (2016) 保护地立法指南. 法律出版社, 北京.]

Li BY, Li JS, Wei DY, Zhu YP (2017) International experience in legislation of national parks and enlightenments to China. Environment and Sustainable Development, 42(5), 20-23. (in Chinese with English abstract) [李博炎, 李俊生, 蔚东 英, 朱彦鹏 (2017) 国际经验对我国国家公园立法的启 示. 环境与可持续发展, 42(5), 20-23.]

Li JH (2019) From national park to park country: Dialogue with Jianlong Zhang, Member of the CPPCC National Committee and Director of the State Forestry and Grassland Administration. Journal of CPPCC, 2019-3-10(09). (in Chinese) [李将辉 (2019) 从国家公园, 到公园国家—— 对话全国政协委员、国家林业和草原局局长张建龙. 人民 政协报, 2019-3-10期第9版.]
Lü ZM (2018) Thinking on the research of environmental law in the new era. Journal of CUPL, (4), 5-14. (in Chinese) [吕 忠梅 (2018) 新时代环境法学研究思考. 中国政法大学 学报, (4), 5-14.]

Lü ZM (2019) Thinking on the legislation of natural protected areas. Environmental Protection, 47(3/4), 20-23. (in Chinese) [吕忠梅 (2019) 关于自然保护地立法的新思考. 环境保 护, 47(3/4), 20-23.]

Qin TB (2018) Several dimensions on national parks legislation in China. Environmental Protection, 46(1), 41-44. (in Chinese) [秦天宝 (2018) 论我国国家公园立法的几个维 度. 环境保护, 46(1), 41-44.]

Sun YH, Chen SY (2004) Proof of making Law of Natural Reserve. Environmental Protection, 32(3), 7-12. (in Chinese) [孙佑海，陈少云 (2004) 关于制定《自然保护区 法》的论证. 环境保护, 32(3), 7-12.]

Tang FL (2018) National parks enter a new era of development in China. China Green Times, 2018-4-2(03). (in Chinese) [唐芳林 (2018) 中国国家公园发展进入新纪元. 中国绿 色时报, 2018-4-2第3版.]

Zhang ZW, Yang R (2016) Discussions on the legislation of Chinese national parks and protected areas. Chinese Landscape Architecture, 32(2), 70-73. (in Chinese with English abstract) [张振威, 杨锐 (2016) 中国国家公园与自然保 护地立法若干问题探讨. 中国园林, 32(2), 70-73.]

(责任编委: 马克平 责任编辑: 周玉荣) 